\title{
Feeding habits of anophelines (Diptera: Culicidae) in 1971-78, with reference to the human blood index: a review
}

\author{
C. GARRETT-Jones \\ 16 Conduit Road, Abingdon, Oxon OX14 IDB, UK \\ P. F. L. Boreham \\ Imperial College Field Station, Ascot, Berks SL5 7PY, UK* \\ C. P. Pant \\ Ecology and Control of Vectors, WHO, 1211 Geneva 27, Switzerland **
}

\section{CONTENTS}

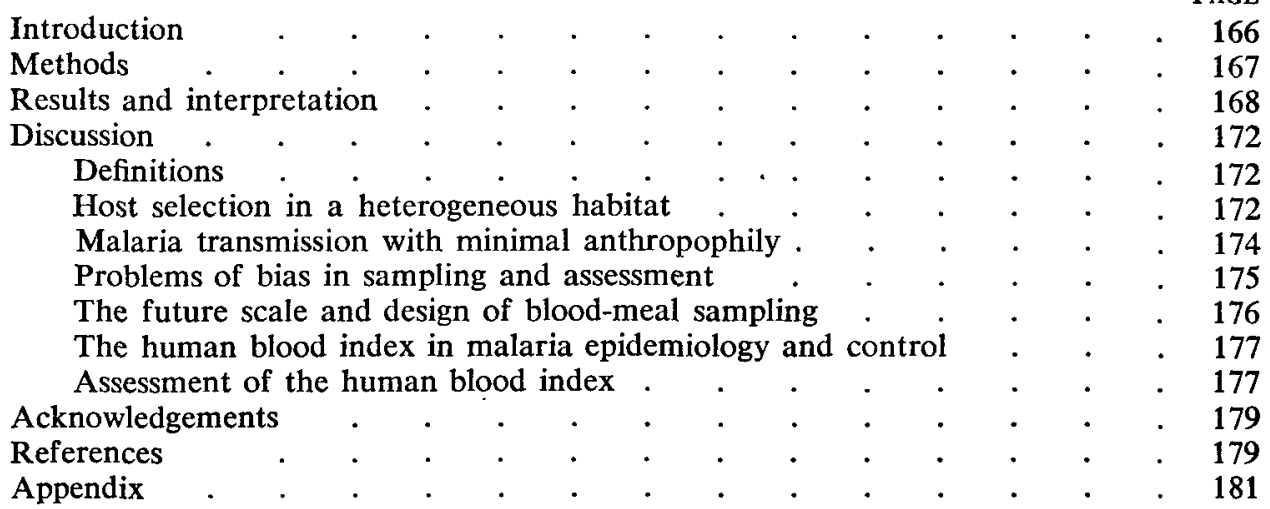

\begin{abstract}
A synoptic view is given of the data amassed by WHO, with technical assistance from the Imperial College of Science and Technology, on the origins of blood-meals in Anopheles samples collected from 1971 to 1978. Attention is focused on the proportion of each sample found to contain human blood and on the problems of interpreting from this the human blood index or degree of biting-contact with man exhibited by vector populations. The difficulties of overcoming bias in sampling, which are formidable in unsprayed areas, are further compounded where the dwellings are treated with a slow-acting residual insecticide which knocks down many engorged mosquitoes before they can be collected from their
\end{abstract}

\footnotetext{
* Present address: Queensland Institute of Medical Research, Bramston Terrace, Herston, Brisbane, Queensland, Australia 4006.
}

** For offprint requests.

(L 3758) 
daytime resting places. There is evidence to suggest that the host-selection patterns of those vectors which are 'opportunistic' feeders may be heavily influenced, even from village to village or from month to month, by the changing availability of alternative hosts, particularly cattle. This suggests in turn that the possibilities of manipulating the degree of mosquito-man contact by encouraging deflection to animals (zooprophylaxis) or by measures to afford a degree of personal protection should not be underestimated by malaria strategists. It may sometimes be found less difficult to reduce the vector's human blood index than it is to measure it, but in view of the epidemiological importance of this parameter, suggestions are put forward for improving entomological field practice in this area. They include a quantitative survey of the biotopes available to the mosquito population as diurnal shelters, a longitudinal survey of the densities of blood-fed females per biotope, and a survey of the numbers and the respective distribution of people and domestic animals available as hosts. The work-load entailed by such a thorough form of investigation, to be repeated where necessary at different seasons of the year, underlines the necessity to concentrate efforts on a small number of localities, carefully chosen for the malaria situations they represent and the vector populations they support. A large-scale blood-meal sampling programme, confined to these selected localities, is most likely in our estimation to yield information of value for controlling malaria vectors.

\section{Introduction}

\section{The object of sampling Anopheles blood-meals}

Blood-meal smears are collected from wild-caught anopheline mosquitoes primarily in order to obtain an indication of the degree of biting-contact, known as the human blood index or HBI, between a specified mosquito population and man. This information may be needed by the field investigator for establishing the status of the mosquito as a known, suspected or potential vector of human disease, especially malaria; it may also be relevant in determining the measures most appropriate for vector control and in evaluating that control. The proportion of any sample from a given population found to have fed on man may vary according to such factors as the site (or biotope) of collection, the man:ox ratio, protective measures in use by the people, the spray status of the locality, the mosquito's homogeneity in selecting a host or its responses to an insecticide. The field worker seeks to understand the reasons for the local and temporal variations within or between populations, the better to discern their implications for malaria control strategy.

The global reviewer has a different task. He has to provide a synoptic view of the degrees of mosquito-man contact indicated over a series of populations according to species, area, year and spray history. The resulting data are unavoidably general, and it is more satisfactory to record a range of values where possible, rather than a single figure representing an average from scattered observations.

\section{Scope of the present review}

Summaries of global data on the host-selection patterns in anopheline mosquitoes, as indicated by precipitin-testing individual blood-meals, were published by Bruce-Chwatt \& Göckel (1960), Garrett-Jones (1964) and Bruce-Chwatt et al. (1966). Together, those reviews covered the period 1955-64, i.e., the first ten years of systematic investigation under the auspices of the World Health Organization (WHO).

Similar results continued to be gathered from 1965 to 1970 and are available in 
WHO's archives, but in 1971 WHO issued directions for the recording of a wider range of circumstantial information. For this reason, we summarise here only the findings from 1971 onwards.

\section{The human blood index (HBI) in malaria control strategy}

The proportion of bites on man by a population of a blood-sucking predator defines that population's human blood index or HBI (WHO, 1963; Garrett-Jones, 1964). In anophelines, the index is required in assessing the reproduction rate of malaria (Macdonald, 1952, 1957) and the mosquito's vectorial capacity (Garrett-Jones, 1964; Black, 1968). Unfortunately, the collection and analysis of blood-meal samples takes us only one step towards the assessment of a vector poulation's HBI. Much additional information is needed, the problems of obtaining which will be discussed below.

In view of the reorientation of national antimalaria programmes called for by the 31st World Health Assembly (WHO, 1978), the possibility of manipulating the vector's HBI in some endemic areas needs to be critically examined. This is a neglected area since in the past faith was pinned on the operational efficiency of residual insecticides. The possible use of cattle or other animals to reduce the vector's HBI and so reduce its man-biting habit (the average frequency with which an individual mosquito bites man) must rest on the study of the actual variations of the HBI between neighbouring populations and within a single population.

\section{Methods}

\section{Sampling, recording and testing}

The standard method of sampling the blood-meals in resting anophelines, recommended to antimalaria programmes by WHO, is set out in WHO (1975, Part II, p. 129). Among the additions to the data required with each sample of smears, the form now provides for data on the local ratio of man to cattle, here called the man:ox ratio (MOR). $\dagger$ Batches of blood-meal samples are sent to a single specialised institution for standard precipitin test analysis as described by Weitz (1956) and Boreham (1972).

\section{Presentation of the summarised results}

A degree of generalisation is inevitable when the results to be summarised represent 36 species of Anopheles sampled in 42 countries over a span of $7 \frac{1}{2}$ years. In deciding how to present this mass of data, we wished to avoid introducing too great a difference from the presentation in the 1966 review (Bruce-Chwatt et al., 1966), in order that the findings of 1971-78 may be meaningfully compared with those of 1955-64.

We cannot emphasise too strongly the fact that the figures tabulated do not, in most instances, represent the findings for any one population of the species named. They represent all the populations sampled in areas of one spray status, in a given country and year. Analogous results from 2 or 3 years are combined only when no marked trend or divergence is evident. Most figures are therefore aggregated values, and any proportion derived from them is no more than a mean, weighted moreover by variations in the numbers collected in different localities. The significance of this limitation will be considered in the discussion.

Four figures are given for each aggregated sample: the total number of smears giving a positive precipitin reaction, followed by the numbers positive for primate blood, for bovine blood (including ox and buffalo but not sheep or goat) and for the blood of all other hosts or host groups included in the testing routine. A percentage reading is added only for the smears found to contain primate blood, and only where the sample yielded 25 or more positive reactions. The primate feeds tested are taken to be on. man, as other primates are rarely present near the sites of capture.

$\dagger$ The term 'man:bovine ratio' would be more precise in reference to those areas where the domestic cattle include buffalo. But ' $m a n$ : ox ratio' is retained in order to avoid any confusion with the mosquito's 'man-biting rate' (MBR). 


\section{Results and interpretation}

The Appendix summarises the findings on all significant samples of Anopheles species from which blood-meals of resting mosquitoes were collected and sent forward through WHO. The hierarchical arrangement of the table is by species (alphabetical), country, year, spray status of area and biotope class. Following Bruce-Chwatt et al. (1966), we use 'biotope' to denote the type of resting place. The separation of two classes of biotope is retained as a convenient way to segregate those biotopes (houses, mixed dwellings, tents, etc. = biotope class $\mathrm{H}$ ) where man is present through the night from those others (animal sheds, stores, vegetation, etc. = biotope class $O$ ) where man is normally not available. This is not the same distinction as the one commonly made between indoor and outdoor resting samples.

The numbers of smears giving only negative reactions (nearly always small numbers that are presumed to be the result of poor collected material or faulty technique). are excluded in order to simplify the data. Meals of mixed origin are counted twice (e.g., as positive for primate and bovine blood), which explains why some totals exceed the number of positive smears shown in column 6.

For purposes of comparison some data referring to 1959-64 are cited. These are taken from Table 2 in Bruce-Chwatt et al. (1966): the ' 1966 Review' mentioned passim in the text.

\section{A. aconitus Dönitz-Indonesia}

According to the 1966 Review, the samples from dwellings (biotope class H) in 1959-64 contained a mean proportion of $22.2 \%$ fed on man in untreated areas. Later sampling in the DDT-sprayed areas showed this proportion reduced to $5.7 \%$ in 1973 and $6.0 \%$ in 1975 . Meanwhile, a contrary trend occurred in the class-O biotopes: in untreated areas the mean proportion fed on man was $2.5 \%$ in $1959-64$ and $0.8 \%$ in 1978, whereas in the DDT-sprayed (or ex-DDT-sprayed) areas from 1972 to 1978 , the proportion varied between 7.8 and $32.9 \%$. (This interpretation differs from that of Joshi et al. (1977), who record for 1975-76 only 3.2\% man-fed from animal sheds and $7.7 \%$ from natural outdoor shelters.)

No similar effect was apparent in areas treated with other (non-irritant) insecticides. Thus, in houses sprayed with fenitrothion, $29 \%$ had fed on man in 1977, while in the class-O biotopes in 1977-78 the proportion was $2.5 \%$ in the malathion-treated area, $3.6 \%$ in the fenitrothion-treated area and $2.0 \%$ in the chlorphoxim-treated area.

\section{A. balabacensis Baisas-Malaysia (Sabah)}

The $25 \%$ fed on man in 1971 in DDT-treated dwellings compares with $76 \%$ in untreated ones in 1959-64.

\section{A. culicifacies Giles-Sri Lanka}

The proportion fed on man in DDT-treated dwellings ranged from $11.8 \%$ in 1976 to $31.7 \%$ in 1977 , while in ex-DDT areas (those last treated more than 12 months before sampling) the range was from 22.6 to $56 \%$. In dwellings treated with malathion, a range from $23.2 \%$ in 1976 to $65.8 \%$ in 1978 was recorded. Pre-spray samples from Sri Lanka in 1959-64 had shown a mean proportion of $32.7 \%$ fed on man, whereas in India in the same period a total of 233 smears revealed no feeds on man. (See Discussion for a note on anomalous findings in Pakistan in 1976-77.)

\section{A. funestus Giles group}

The samples of the $A$. funestus group were not identified to species level. With the possible exceptions of the outdoor samples from Kenya in 1972 and Sudan in 1971, they may be taken to refer to $A$. funestus s.s. This vector is generally so endophilic that only small numbers of blood-fed females can be collected from biotopes other than human 
dwellings; moreover, since all such females are apt to disappear from treated houses and indeed from treated areas, the record of blood-meal samples tested looks somewhat lopsided. All the larger samples in the Appendix are from untreated dwellings, where the proportion fed on man ranged from $91 \%$ in Mozambique to $100 \%$ in Kenya (Kisumu, 1971), Malawi, Togo, and parts of Nigeria. Even in mixed dwellings at Kisumu in 1973 , as many as $93.2 \%$ of resting females had fed on man.

The small samples collected from O-class biotopes at Kisumu illustrate well the limitations of the simplified $\mathbf{H}$ and $\mathrm{O}$ classification. The proportions fed on man were $0 / 11$ in $1972,10 / 10$ in 1973 and $9 / 13$ in 1975 ; but these records refer in fact to a different biotope each year, namely pit-shelters, animal sheds, and granaries.

Sampling of blood-meals from the $A$. funestus group was more extensive in 1959-64 (the 1966 Review), when the proportion fed on man ranged from $68.7 \%$ in Uganda to $99.2 \%$ in Liberia and $100 \%$ in Togo in untreated dwellings. Some high figures were also recorded in DDT-treated dwellings in Cameroun and Upper Volta and in dieldrin-treated ones in Madagascar. The proportions that had fed on man from O-class biotopes in that period and in untreated areas ranged from $0 \%$ in Rhodesia to $99.5 \%$ in Togo. In DDT-treated areas, the mean proportion fed on man was $67.0 \%$ in Cameroun, $0 \%$ in Mozambique and $19.8 \%$ in Upper Volta.

\section{A. gambiae Giles complex}

An extended discussion of the geographical distribution, feeding and resting habits of each member of the $A$. gambiae complex will be found in White (1974).

Ethiopia.-The studies tabulated were performed without cytogenic analysis of the species represented. They appear to indicate a declining man-fed proportion from year to year in the samples taken from biotope-class H. This trend continued from 1971 to 1973, when large numbers were collected from DDT-sprayed dwellings. Samples from biotope-class $O$ in the sprayed areas in 1972-75 similarly showed a declining proportion fed on man, while the levels in 1972 and 1973 did not differ significantly from the concurrent levels in dwellings.

In 1973, a study at the untreated district of Jimma by White (pers. comm.) showed that the complex was represented by $A$. arabiensis Patton and $A$. quadriannulatus (Theobald). The relative resting-densities of the two species varied according to biotope and to some degree according to season. From January to August 1973, the mean proportion of $A$. arabiensis was $99.5 \%$ in human dwellings, $87 \%$ in mixed dwellings, $46 \%$ in animal sheds and $43 \%$ in pit-shelters. The specific proportions of these samples feeding on man have not yet been determined, but we have data on the man-fed proportion of A. gambiae s.1. in each biotope during this study (White, 1974; Boreham, 1975). The proportions with human blood were as follows (the second bracketed figure representing mixed feeds in each case):

$\begin{array}{lccc}\text { Biotope } & \text { Sample } & \text { No. man-fed } & \% \text { man-fed } \\ \text { Human dwellings } & 233 & (185+6) & 82 \cdot 0 \\ \text { Mixed dwellings } & 1057 & (309+76) & 36 \cdot 4 \\ \text { Animal sheds } & 723 & (21+5) & 3 \cdot 6 \\ \text { Pit-shelters } & 99 & (0+2) & 2 \cdot 0\end{array}$

This study differs from others in that mixed feeds were expressly looked for. An analysis to show whether the sibling species differed in this respect would therefore be of particular interest. The rather high incidence $(7.2 \%)$ of patent mixed feeds found in the mixed dwellings suggests a substantial degree of cryptic multiple feeding in at least one of these A. gambiae populations (Boreham \& Garrett-Jones, 1973).

Kenya.-In the years under review, three separate field research studies on the A. gambiae complex were carried out in the Kisumu area of western Kenya. The results of these are distinguished as Kisumu-a, $-b$ and $-c$ in the relevant entries in the Appendix. Kisumu-a was a village-scale insecticide trial in 1971 in the Kano Plain to 
the east of Kisumu (Joshi et al., 1973; Fontaine et al., 1975). Kisumu-b was the largescale follow-up to this in 1972-76, a stage-VII trial of fenitrothion, carried out in the hilly Seme District to the west of Kisumu (Joshi et al., 1975; Service et al., 1978; Fontaine et al., 1976, 1978), and Kisumu-c was a separate entomological investigation in 1974-75 in and around the Kano Plain by Highton et al. (1979). All three studies concern the two principal malaria vectors of the $A$. gambiae complex: $A$. arabiensis and $A$. gambiae s.s.

Certain comparisons may be drawn from the Appendix between the patterns of host selection revealed by each study. Under $A$. gambiae s.l. are entered the findings in samples from 1971 to 1973 which were not submitted to specific identification. The man-fed proportion differs in each instance, and for a different reason: in 1971 (Kisumu-a), it was down to $67 \%$ in the untreated dwellings on account of the predominance of $A$. arabiensis in the Kano Plain (see below). That it was still lower $(39.4 \%)$ in dwellings treated with fenitrothion is attributed by Joshi et al. (1973) to the knockdown of indoor-feeding females before the morning sampling collection and their replacement by others which had entered after feeding out-of-doors. The findings from Kisumu-b in 1972 (95.1\% man-fed in untreated dwellings and $21 \%$ in pit-shelters) may perhaps reflect the typical pattern of host selection where $A$. gambiae s.s. and $A$. arabiensis are about equally abundant. The lower index of $86.8 \%$ in 1973 may be due to the fact that some mixed dwellings were used, in that year only, to represent biotope-class $\mathbf{H}$.

Among the blood-fed $A$. gambiae s.l. females determined to species in 1972, those of $A$. arabiensis in dwellings (class $\mathrm{H}$ ) included $92.4 \%$ man-fed, compared with a proportion of $95.8 \%$ man-fed in $A$. gambiae s.s. These samples were drawn from the whole of the Kisumu-b project area. The proportions fed on man were lower, and reversed, in the dwellings of two sampling areas which remained unsprayed in 1974-75: $85.9 \%$ in $A$. arabiensis, $80.0 \%$ in $A$. gambiae. It is of interest that $A$. arabiensis also showed the higher man-fed proportion $(6.1 \%$ versus $4 \%$ ) in the granaries (class 0$)$ at that time, and again in the dwellings of the area sprayed with fenitrothion $(28 \%$ in A. arabiensis vs. $24.3 \%$ in $A$. gambiae). However, these indices must be read in the light of the fact that $A$. gambiae constituted on average $71.6 \%$ of the house-resting fed females in the unsprayed areas but only $20.2 \%$ of those resting in granaries, while larval determinations suggested the mean densities of the sibling species were almost equal (Service et al., 1978). Earlier, great seasonal variation in the relative abundance of house-resting $A$. arabiensis and $A$. gambiae was demonstrated by Joshi et al. (1975).

Meanwhile, in the Kano Plain, study Kisumu-c showed in the house-resting blood-fed samples an over-all arabiensis: gambiae ratio of $8 \cdot 3: 1$. This figure, however, conceals a ratio of no less than $15.4: 1$ in the six sampling localities in the plain itself, against a ratio of $1: 5.3$ in two villages in the foothills. The granaries sampled in a single locality in the plain yielded $144 \mathrm{~A}$. arabiensis but only $3 \mathrm{~A}$. gambiae, a ratio of $48: 1$.

In the house-resting $A$. arabiensis in this study, the mean proportion fed on man in the eight localities sampled was $43.4 \%$; the range, probably governed by differing man: cattle ratios, was between 15 and $84 \%$ in the four plain localities where 25 or more smears were collected from this species. In $A$. gambiae, the corresponding mean man-fed proportion was $81.7 \%$; samples of over 24 smears were collected only from one flood-plain and one foothill locality and showed, respectively, 75 and $94 \%$ fed on man. In the group of granaries sampled, $3.5 \%$ of $A$. arabiensis and 1 out of 3 A. gambiae were man-fed.

Nigeria (Kano State).-The A. gambiae complex was intensively studied in a WHO field research project to test the impact of propoxur on malaria transmission (Molineaux \& Gramiccia, 1979). The two members of the complex, A. gambiae and A. arabiensis, are shown as undifferentiated for 1971-73 but tabulated separately for 1974 and 1975 . In 1973-75 when sampling was concentrated on the settled villages where oxen were scarce or absent and sheep, goats, and donkeys were generally outnumbered by man, 
the proportion of $A$. gambiae s.l. that had fed on man was consistently over $90 \%$ and sometimes reached $100 \%$. This was true of both species, $A$. arabiensis showing an index of $93.3 \%$ and $A$. gambiae $97 \%$ in 1974 . The application of propoxur in 1975 had no apparent impact on this pattern of host selection.

A lower general index, 87.7\%, was recorded in houses for 1971 , together with an index of $23 \%$ in an outdoor sample. The field records show that the latter sample was collected at Sugungum, a village which held larger numbers of Bovidae and Equidae than most. Even the house-resting samples of that place proved to contain only 62 out of $96(65 \%)$ fed on man; hence the depressed index.

A more striking deviation is shown under A. gambiae s.l for 1972, with an overall proportion of $64.2 \%$ man-fed in an aggregate of 810 indoor-resting mosquitoes. All of these were collected by $M$. Coluzzi at one locality, Jirima, where the mosquitoes occupied two sharply-contrasting habitats. The analysis of their comparative numbers and host-selection behaviour (Coluzzi et al., in press) will be examined in the Discussion.

Nigeria (Bendel State).--In most localities of Benin City and in Sapele and Auchi Districts, no oxen were present at the time of blood-meal sampling. It was found that A. gambiae s.s. is the predominant member of that complex in the rain-forest zone but is replaced by $A$. arabiensis in urban areas such as Sapele (A. Smith, unpublished report to WHO, 1979). Samples of both these species, and those of $A$. funestus, $A$. hargreavesi Evans and $A$. nili (Theobald), had fed almost exclusively on man.

A study by White \& Rosen (1973) of the HBI of the A. gambiae complex under different housing conditions near Kaduna, Nigeria, will be referred to in the Discussion.

Togo.-The sample of 88 smears " mostly collected in outlet window traps on DDT-sprayed dwellings" should be noted. All the females had fed on man, and it is possible that some proportion of these would have survived their contact with the irritant insecticide and would go to increase the numbers of man-fed $A$. gambiae making use of unsprayed resting places. The records contain surprisingly few samples similarly collected in order to monitor the 'escape ' effect.

\section{A. maculatus Theobald-Nepal}

Strong zoophily in this species is suggested by the finding of no human blood in a sample of 96 smears from DDT-sprayed houses. This agrees with a similar zero finding in the O-class of biotopes, reported in the 1966 Review. However, we have so far seen no results from any sample collected in untreated human dwellings.

\section{A. maculipennis Meigen group}

A. labranchiae Falleroni-Morocco.-The index of $34 \%$ man-fed in unsprayed and in formerly-sprayed houses (1971) appears to correspond to similar figures in the 1966 Review. The latter, however, shows no impact of DDT-spraying, whereas in 1971 the index in the treated houses was reduced to $2 \%$. As in some other vectors, it would seem that the spraying of DDT may have increased the proportion of man-fed females using unsprayed $O$-class biotopes from about $1 \%$ before spraying to between 8.5 and $11.7 \%$ in later periods. In this vector, a higher index of anthropophily is recorded in Tunisia than in Morocco; but this may be due to taxonomic differences between the populations sampled. White (1978) argued that the Moroccan populations may be referable to $A$. sicaulti Roubaud.

A. sacharovi Favr-Greece.-A special study of multiple feeding in this species was made at Thermopylae in 1970 (Boreham \& Garrett-Jones, 1973). Its implications are discussed in the following section. The Appendix includes only later samples dating from 1971 and shows a man-fed proportion of $61.1 \%$ in the houses of Thermopylae. This is far higher than the proportions of $8-9 \%$ recorded from Greek houses in the 1966 Review. 


\section{A. multicolor Cambouliu}

The limited sampling of this species appears to indicate wide geographical variations in its degree of contact with man. Combining the present evidence with data published in 1966, house-resting samples were 38\% man-fed in Morocco, 66 and $55 \%$ in Tunisia, $91 \%$ in Libya and 3\% in Saudi Arabia. The houses sampled were unsprayed in all countries except Libya, where they had formerly been sprayed with DDT.

\section{A. nili (Theobald)}

The consistently high indices shown earlier in house-resting samples of this species from Ghana and Upper Volta are now confirmed in the Congo and Togo.

\section{A. pharoensis Theobald}

The indoor sample from Ethiopia showed a man-fed index of $94 \%$, which is much higher than the earlier figures recorded from the Sudan, Egypt or Cameroun.

\section{A. sergenti (Theobald)}

The man-fed index in houses is variable, as in the sympatric A. multicolor. The 1966 Review recorded $6 \%$ in Morocco and $35.0 \%$ in Saudi Arabia, while the Appendix shows $45 \%$ in Tunisia.

\section{Discussion \\ Definitions}

The human blood index (HBI) was defined (WHO, 1963) as "the proportion of freshly fed Anopheles giving a positive precipitin reaction for human blood". Garrett-Jones (1964) suggested that the HBI " should refer to a representative sample of a single species, collected in a stated area and period." A more precise definition relating the HBI to the sum of conspecific females within a single interbreeding population is needed, such as: " the HBI is the proportion of feeds taken on man by the members of a specific and specified mosquito population, expressing the degree of mosquito-man biting contact exhibited by that population."

The HBI of a population can only be assessed by sampling, and it is never possible to know whether the samples taken are fully representative. The problems of sampling bias will be discussed further below. In the past, the term HBI has been used somewhat loosely. It has been applied on the one hand to samples that represent only parts of a given population, thus: "The HBI of mosquitos sampled from houses should be considered separately from the HBI of those collected at the other 4 sites " (Boreham \& Garrett-Jones, 1973). In this instance, the true HBI of the population studied would depend on a proper combination of the proportions fed on man in the various biotopes, having regard to data on the mosquitoes' biotopic distribution.

At the other extreme is the temptation to assign the HBI label to aggregated samples representing a wide variety of conditions and spanning a long period or a large area. Aggregation is unavoidable in a global review, but we have avoided applying the term HBI to aggregated values by referring instead to the 'average proportion fed on man.'

In any locality supporting several Anopheles species, the HBI of their respective populations is likely to differ. Such differences, moreover, may be consistent over a wide area and may demonstrate contrasting degrees of anthropophily and zoophily from one species to another, but the degree of contact with man will also vary, sometimes widely, within each species according to local (or temporal) conditions. This is why it is better to refer to the HBI of a population than to that of a species as a whole.

\section{Host selection in a heterogeneous habitat}

In many malarious countries, the night-time distribution of domestic animals within a typical village differs from the distribution of the people. The resulting variations 
in the man:ox ratio (MOR) are relatively slight in some cases but extremely wide in others. The existence of such variations in any locality means that its mosquito populations necessarily inhabit a territory which is heterogeneous in the opportunities it offers for host selection. How much difference is this heterogeneity likely to make, from house to house or from compound to compound, in the density of a vector population and in the proportion of blood-meals it obtains from man?

Fortunately we have some clear-cut data which may help answer these questions. In August-September 1972, M. Coluzzi, while working with the WHO Malaria Research Project in the Garki District of Kano State, Northern Nigeria, collected over 800 blood-meal smears from mosquitoes of the $A$. gambiae complex at the unsprayed village of Jirima. At that place (as elsewhere in the dry Guinea savanna), the settled villagers are joined seasonally by nomadic herdsmen who pitch their camp of small temporary huts less than $2 \mathrm{~km}$ from the village. The community thus contains two contrasting types of dwelling and more important, two completely different man:ox ratios. In the village itself, Coluzzi estimated a man:ox ratio of 50 , while in the adjacent Fulani camp his estimate was $0.077(1: 13)$.

A. gambiae s.l. was sampled indoors in both parts of the locality and gave overall proportions of $64.2 \%$ fed on man, $30.5 \%$ on ox and $5.3 \%$ on the other domestic animals present (mainly sheep, goat and donkey). The proportion fed on man was well below the index recorded in the same district in other years when sampling was confined wholly or mainly to the dwellings of the settled villagers. The reason becomes apparent in the light of the identification of 747 blood-fed mosquitoes (Coluzzi et al., in press). It shows unequal distribution of the two species represented in the sample, compounded by divergences in the interspecific and intraspecific patterns of host-selection.

TABLE I. Analysis of blood-meals from mosquitoes of the A. gambiae complex sampled in two habitats in Jirima in northern Nigeria in August-September 1972 *

A Village sample

Camp sample

Total

B Distribution of species Village Camp

C Man-fed, in village Man-fed, in camp

Total

D Distribution of bites on man in village in camp

E Proportion fed on man in village in camp

Total
A. gambiae s.s.

$129(39.4 \%)$

$84(20.1 \%)$

$213(28 \cdot 5 \%)$

$129(60.5 \%)$
$84(39.5 \%)$

$129(44.0 \%)$

$66(39.3 \%)$

$195(42.2 \%)$

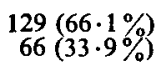

$100 \%$ (in 129)

$78.6 \%$ (in 84)

$91.5 \%$ (in 213)
A. arabiensis

$199(60.6 \%)$

$335(79.9 \%)$

$534(71.5 \%)$

$199(37.4 \%)$
$335(62.6 \%)$

$165(56.0 \%)$

$102(60.7 \%)$

$267(57.8 \%)$

$165(61.8 \%)$

$102(38.2 \%)$

$82.9 \%$ (in 199)

$30.4 \%$ (in 335)

$50.0 \%$ (in 534)
Total

328
419

747

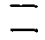

294

168

462

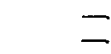

$89.7 \%$ (in 328$)$

$40 \%$ (in 419)

$61.9 \%$ (in 747)

- Data from Coluzzi et al. (in press).

The results are shown in Table I. A. arabiensis was the more prevalent vector in both village and camp (Section $\mathrm{A}$ ), forming about $61 \%$ of the village sample and $80 \%$ of the camp sample. More than half $(60 \%)$ of the $A$. gambiae occurred in the village, while about $63 \%$ of the $A$. arabiensis occurred in the camp (Section B). This suggests a pronounced difference in the host orientation of the two species. Coluzzi noted that the higher proportion of $A$. arabiensis in the camp "was already evident a few days after the Fulani settled in the area." 
Section $\mathrm{C}$ shows that more $A$. arabiensis than $A$. gambiae fed on man in the village $(56 \%)$ and the camp (about $61 \%$ ) alike. However, disregarding any difference of size between the habitats, $A$. gambiae delivered about $66 \%$ of its bites on man in the village and $A$. arabiensis about $62 \%$ (Section D). Finally, the strong influence of divergent man:ox ratios on host selection is demonstrated in Section E. Nearly $90 \%$ of both vectors combined had fed on man in the village, against only $40 \%$ of those in the camp; but the influence was distinctly weaker in A. gambiae (100 vs. $79 \%)$ than in A. arabiensis ( 83 vs. $30 \%$ ).

Given the nature of the terrain in Garki District, it is likely that Coluzzi's houseresting samples represented without bias the blood-fed population of each vector. The findings may adequately reflect the $\mathrm{HBI}$ if we suppose that sampling was 'equal' in the two habitats, i.e., that the samples reflected the numbers in contact with similar proportions of the people in the village and the camp, respectively. On this assumption, the estimated mean HBI at Jirima at that time would have been about 0.92 in $A$. gambiae and 0.50 in $A$. arabiensis.

The much lower index of mosquito-man contact estimated for $A$. arabiensis than for $A$. gambiae is supported by Coluzzi's findings on the sporozoite rates of the two species in 1972 (Coluzzi et al., in press). At three other unsprayed villages, the average rate was $9.44 \%$ (in a sample of 530 ) in $A$. gambiae as against $4.02 \%$ (of 274 ) in $A$. arabiensis. In Jirima village and camp, the rates in $A$. gambiae were down to $4.01 \%$ (199) and $4.35 \%(69)$, respectively, suggesting that deflection to cattle reduced infectivity by half, even in this vector. Meanwhile, in A. arabiensis, samples of 329 in the village and 182 in the camp were all negative for sporozoites.

White \& Rosen (1973) compared the HBI in members of the A. gambiae complex captured indoors in two sections of a village near Kaduna, Nigeria: the Hausa section and the Fulani section, the latter having a large cattle herd. The HBI of 102 females from the Hausa section was $100 \%$, while $54 \%$ of 91 females from the Fulani camp had fed on man and the remaining $46 \%$ on cattle. Cytotaxonomic identifications of $A$. gambiae s.s. and $A$. arabiensis from the two sections were made. Whereas in the Hausa section both species had an HBI of $100 \%$ (85 and 9 specimens examined, respectively), in the Fulani section $A$. gambiae had an HBI of $88 \%$ (50 examined) in contrast to $39 \%$ (36 examined) in $A$. arabiensis. The authors concluded that a considerable number of both $A$. gambiae and $A$. arabiensis were feeding on cows and resting indoors and that the HBI of $A$. gambiae was significantly higher than that of $A$. arabiensis in the presence of cattle.

\section{Malaria transmission with minimal anthropophily}

Between January 1976 and May 1977 the host-selection patterns of various mosquitoes in Punjab Province of Pakistan were investigated by Reisen \& Boreham (1979). Active transmission of both Plasmodium vivax and $P$. falciparum was demonstrated at the time in the villages selected for blood-meal sampling. In spite of this, the proportions of samples found that had fed on man were very low in all the Anopheles species captured: $0.58 \%$ in an aggregate sample of $1883 \mathrm{~A}$. culicifacies, $1.1 \%$ in $95 \mathrm{~A}$. fluviatilis James, $0.7 \%$ in $300 \mathrm{~A}$. annularis Wulp and $0 \%$ in $817 \mathrm{~A}$. stephensi Liston, $90 \mathrm{~A}$. pulcherrimus Theobald and $40 \mathrm{~A}$. subpictus Grassi. One out of 7 A. nigerrimus Giles had fed on man.

The man:ox ratio (which in this area includes buffalo as well as ox) in five of the villages ranged from 6.8 at Ahmad Park to 0.64 at Sattoki. The majority of the anopheline samples, including $98 \%$ of the $A$. culicifacies, were taken in animal sheds, and in some localities none of the capture stations was a human dwelling. It is believed that this introduced little bias since practically all the biting contact was occurring out-of-doors, where man and cattle spend the night during nine months of the year. That view may not be entirely supported by their results at Khano-Harni where 2 of 209 meals collected from $A$. culicifacies in sheds and 2 of 36 in houses were from man. 
Even so, it remains unexplained how such apparently zoophilic vector populations could maintain malaria endemicity at such high levels.

Reference to the earlier review (Bruce-Chwatt et al., 1966, Table 2) shows a zero man-fed index in Indian $A$. culicifacies and the same in Pakistan $A$. stephensi, which are both important vectors over wide areas, so this is no new problem. It suggests the need for a fresh approach to blood-meal sampling in southern Asia, an approach which would begin with a careful count of the biotopes locally available to the vectors and the assessment of their respective densities in each biotope. That might perhaps infer a substantial incidence of mosquito-man contact in one or more of the species, even if the HBI does not reach a high level. Special efforts may be needed to collect good numbers from human dwellings.

\section{Problems of bias in sampling and assessment}

The sampling in the two Nigerian studies described registers a big advance from the general run of sampling, thanks to the separate analysis made of the samples from disparate parts of the one locality, but it also serves to highlight some difficulties in avoiding sampling bias.

First, there may be, in any similar situation, an unrecorded disparity in the prevalence (i.e. availability) of the alternative resting-places, be they classes of biotope or dwellings adjacent to contrasting densities of cattle. Thus, it might be misleading to compare the mosquitoes from (say) 10 dwellings in a village and 10 in a camp, if the whole locality comprised 100 village dwellings and only 20 camp dwellings. A massive correction factor would be needed before the HBI of a population could be derived from the findings.

A second variable to be considered is the density of blood-fed mosquitoes in different capture stations. This might tend to offset or even cancel out the first variable. For example, there might be 50 mosquitoes per camp dwelling as against 10 per village dwelling, but the bias might equally well be compounded by the disparity of densities.

The items of information mentioned, that is, the relative prevalence of two or more biotopes used by resting females and the relative densities of blood-fed females in each biotope, are essential data for interpreting the HBI of any vector population (GarrettJones, 1964). The need is for some simple 'geographical reconnaissance' such as is traditionally used in anti-malaria campaigns only to assess the consumption of insecticide, not to give epidemiological meaning to the observations of the entomologist.

A third and serious difficulty in the unbiased sampling of resting mosquitoes is its excessive laboriousness in certain biotopes, notably in vegetation, fissures and burrows, compared to its relative ease in ordinary domestic buildings. The knockdown spray, most commonly used indoors, may be impracticable in outdoor situations or else too inefficient to yield a sample large enough for quantitative assessment. Moreover, vegetation, unlike housing, tends to be continuous rather than discrete, and it is difficult to see how field workers might ' balance ' their sampling efficiency between such different biotopes. Artificial outdoor shelters sometimes yield good numbers, but they can hardly be taken to reflect the proportion of a vector population digesting its blood-meals in natural shelters. A better biotope for sampling the vectors in some parts of Africa would appear to be provided by the granaries belonging to each compound (Fontaine et al., 1978; Highton et al., 1979). It may not be practicable to use them, however, at times when they are full of grain.

Two other problems of sampling should be mentioned: first, the great scarcity in the morning of resting mosquitoes in structures that have been sprayed with insecticide. This may mean that lethal contact affects the mosquitoes biting man more than those biting cattle and that knockdown occurs after feeding but before the morning sample is collected. That could lead to a distorted assessment of the true situation by an underestimation of the proportion of vectors feeding on man. Not only may man-fed mosquitoes be absent from the walls (though possibly present for a time on the floor), 
but in some cases they are replaced by animal-fed individuals entering the treated houses in the last hour or two before the morning sampling. This was the conclusion of Joshi et al. (1973) with regard to A. gambiae s.l. in the houses that had been treated with fenitrothion at Kisumu, Kenya.

Secondly, a movement in just the opposite direction appears to be substantiated as an effect of DDT-spraying, where the irritability of the blood-fed mosquitoes causes them to leave the treated houses and seek alternative shelter. Thus in several vectors, as noted in the Results and the Appendix, there is an increase in the proportion of outdoor-resters fed on man following the application of DDT. Where this response occurs, it may indeed facilitate the unbiased assessment of the HBI in sprayed areas. It should at all events mitigate any underestimation of the degree of mosquito-man contact persisting.

\section{The future scale and design of blood-meal sampling}

A major problem in blood-meal sampling is the appropriate size of samples from any one vector population, the frequency of repetition and the number of populations or localities to be sampled. Rational decisions on these matters can only be reached within the malaria control service concerned. No full discussion of the relevant factors can be given here, but it is considered that they should depend on identification of the purpose of sampling in each given situation. Thus, sampling may be related to problems of epidemiology (see the next section), to localised evaluation of zooprophylactic control or, especially, to existing knowledge of vectors' host-selection patterns.

A vector such as $A$. funestus, which is at once highly anthropophilic and highly responsive to most insecticides, does not appear to warrant repeated routine sampling of its blood-meals. The same might be said of $A$. gambiae s.l., $A$. hargreavesi and other vectors in rain-forest areas where cattle are scarce and the mosquitoes are known to depend almost entirely on human blood. At the other extreme, little purpose may be served by repeated sampling over the years in species which have consistently shown minimal contact with man, unless of course there are other grounds for suspecting them to be vectors.

These exclusions imply that the main effort in blood-meal sampling should be concentrated on those vector populations which show an opportunistic habit, feeding on man or on domestic animals in varying degrees according to local or seasonal circumstances. One circumstance which invites opportunism of this kind is human 'exophily' by night, creating an enhanced probability of outdoor transmission.

Small samples of under 25 blood-meal smears per population and biotope are never as helpful as larger ones, although they may provide valuable information where a known or potential vector is difficult to collect in any numbers. Those conditions, whether imposed by nature or by human interventior, demand an extra effort on the part of the investigator, to collect adequate samples from every available biotope. It would be advantageous to analyse locally, rather than remotely, the proportions of meals taken from man in such samples, as these data may have immediate practical value. For this purpose, a portable blood-meal test-kit is being developed (Boorman et al., 1977).

Larger samples representing selected vector species should continue to be collected for in-depth analysis, in pursuance of longitudinal research studies on vectorial capacity in Anopheles. It is suggested that from one to three species prevalent in a given climatic zone might be selected for this purpose. Within the zone, from two to five (unsprayed) localities might then be selected for the sampling, having the same climate but differing in their man : ox ratios, in availability of resting biotopes, or in malaria or filarial endemicity. The sampling target might be from 100 to 200 smears per species, locality and biotope, repeated monthly through the season of abundance of each species.

It is axiomatic that the information recorded and updated in longitudinal studies should include all the parameters required for computation of the HBI (see below). 
These might be seen as the minimum acceptable input. Increased value will attach to the findings if further factors, such as feeding frequency, the parous proportion and the sporozoite rate (if any) are studied concurrently.

\section{The human blood index ( $H B I)$ in epidemiology and control}

Black (1968, p. 202) wrote that "every effort should be made to find means of measuring more accurately the factors of vectorial capacity in field practice". The HBI is one of those factors (Garrett-Jones, 1964). Together with the vector's feeding frequency, density, receptivity to infection and expectation of infective life, it determines the daily reproduction rate of malaria, and likewise that of bancroftian filariasis. Measures to halt or reduce transmission are usually aimed at the most vulnerable factors, density and life expectancy, but a reduction brought about in the HBI might be as effective in areas of low endemicity, allowing for the fact that the rate of transmission varies as the square of this factor.

Insecticidal campaigns exert selection pressure and may provoke unwanted reactions, such as physiological resistance or behavioural avoidance in the vector. There is no reason to think that steps to modify its host selection, for example by zooprophylaxis, would lead to similar untoward effects. Measures of this type need have no ecological side-effects and so readily are they understood by the people at risk, that certain herding communities have practised deflection to animals for centuries.

Where anti-mosquito measures are not aimed expressly at reducing the HBI, any incidental impact on that index is nevertheless worth monitoring. Even more relevant would be observations to assess the impact on vector-man contact of any measures aimed deliberately at deflecting the mosquitoes from man to alternative hosts. Among these, we may include protective clothing, chemical repellants, bed-nets, smoke coils, window-screens, tree or hedge barrie:s and the deployment of cattle on the vector's flight path. Such devices must have been in use for many years in various countries where malaria is endemic. It is disappointing, therefore, that we know of no single report to WHO of field work to assess their impact on the HBI.

The measures referred to may yet prove to constitute a technology appropriate for vector control, particularly in rural areas. They may often be brought into effect by the community itself with a minimum of effort. They are thus better adapted to obtaining that participation of the community which is laid down as one of WHO's anti-malaria programme principles (WHO, 1978) than measures involving the centralised distribution of drugs or of insecticides can be. Furthermore, measures to deflect vectors from biting man would be applicable in most endemic areas of the world, irrespective of which of the four " tactical approaches to malaria control" (WHO, 1978) is deemed appropriate. Measures of vector deflection could be added for example to approach No. 1, aimed only at the "reduction/prevention" of mortality from malaria.

\section{Assessment of the human blood index ( $H B D$ )}

We saw that a single population of mosquitoes may occupy two distinct habitats, such as a settled village and an adjacent nomadic camp in Nigeria. It might be argued that villages everywhere are surrounded by contrasting habitats, namely open or wooded country, which provide the major breeding places for most rural mosquito populations. Therefore, the distribution of the biting and the fed females, and their selection of hosts, should preferably be studied by sampling them in the countryside as well as within the village. However, because comparable sampling in these habitats is seldom practicable, entomologists usually limit their sampling to the village and its immediate environs, treating this 'peri-domiciliary area' as a single habitat. That can be justified where circumstances suggest that the bulk of biting-contact between mosquito and man occurs within the peri-domiciliary area.

Within such an area, there are, by definition, at least two available biotopes, the indoor and the outdoor. Most of ten there are more than these two, since the buildings 
in the village vary in their function, structure, microclimate and choice of vertebrate hosts. Out-of-doors again, the nature of the ground-cover may present a diversity of biotopes, to which the entomologist adds when he provides ' artificial outdoor shelters.'

Clearly, the HBI of a vector population cannot be estimated simply by observing the proportions fed on man in samples collected from the various biotopes. Information is also needed on the relative prevalence of each biotope and the average density of blood-fed mosquitoes in each. A biotope can be disregarded only when it has been shown to harbour no significant part of the blood-fed population.

The analysis of good numbers of blood-meals from each biotope is essential. Where a biotope has been treated with residual insecticide, it will be necessary to seek a means of collecting the fed mosquitoes after knockdown. Failing that, an attempt should be made in other ways to count the vectors feeding within the treated biotope and those entering it after feeding.

Even if all the data mentioned have been collected in a given place, the computation of the vector's HBI may still be an involved process where several distinct biotopes have to be separately considered. Fortunately, there are only two major biotopes in a good many cases, and where the blood-fed females use three or more biotopes the densities and the proportions fed on man may prove to be sub-equal. For the purpose of calculating the vector's biotopic distribution, the findings in these 'sub-equal ' biotopes may then be combined and averaged without introducing bias.

Bearing this in mind, we may consider how the $\mathrm{HBI}$ is to be computed in the simplest case, where the fed mosquitoes are restricted to two main biotopes (or their equivalent). A formula expressing the index and the elements from which it is composed are given in Table II. The symbols and definitions in the table will serve to clarify the

\section{TABLE II. Elements needed to calculate the human blood index (HBI)} of mosquito populations

\begin{tabular}{|c|c|c|}
\hline Symbol & Definition $^{1}$ & Terminology suggested \\
\hline $\begin{array}{l}n_{1} \\
n_{2}\end{array}$ & $\begin{array}{l}\text { No. of dwellings } \\
\text { No. of sheds }\end{array}$ & Prevalence of biotopes \\
\hline $\begin{array}{l}x \\
y\end{array}$ & $\begin{array}{l}\text { No. of fed vectors per dwelling } \\
\text { No. of fed vectors per shed }\end{array}$ & Biotopic fed densities \\
\hline $\begin{array}{l}n_{1} x \\
n_{2} y\end{array}$ & $\begin{array}{l}\text { Size of fed population in dwellings } \\
\text { Size of fed population in sheds }\end{array}$ & Biotopic blood-fed distribution \\
\hline $\begin{array}{l}p \\
q\end{array}$ & $\begin{array}{l}\text { Proportion found fed on man in } \\
\text { dwellings } \\
\text { Proportion found fed on man in sheds }\end{array}$ & Biotopic man-fed index \\
\hline $\begin{array}{l}n_{1} \times p \\
n_{2} y q\end{array}$ & $\begin{array}{l}\text { Size of man-fed population in } \\
\text { dwellings } \\
\text { Size of man-fed population in sheds }\end{array}$ & Biotopic man-fed distribution \\
\hline$\frac{n_{1} x p+n_{2} y q}{n_{1} x+n_{2} y}$ & $\begin{array}{l}\text { Proportion of whole population fed } \\
\text { on man }\end{array}$ & Human blood index of population \\
\hline
\end{tabular}

distinction between those terms which might otherwise be found confusing. Thus, the biotopic distribution of any class of mosquitoes (be they males, females, blood-fed females, infective females, etc.) is not the same thing as its biotopic densities but is a function of these densities and of the relative prevalence of the respective biotopes. Again, a mosquito's biotopic distribution is clearly distinct from its seasonal and geographical distribution.

We know of no field study so far, in which the HBI of an anopheline population has been assessed in the manner suggested. In most investigations, some of the necessary 
input data go unrecorded, but it is possible that data collected at Kisumu, Kenya, which are to be analysed elsewhere, may permit computations of HBI values in certain $A$. gambiae and $A$. funestus populations. This formula, wherever applied, should yield better estimations than the unweighted means of the man-fed proportions in $\mathbf{H}$ - and O-class biotopes adopted by Garrett-Jones (1964). It is natural, however, that public health authorities should discount the relevance of the HBI for malaria epidemiology and control until serious attempts are made to measure it without bias.

\section{Acknowledgements}

We wish to thank Drs. J. Hamon, N. G. Gratz, J. H. Pull, L. Molineaux and D. A. Muir, all of WHO, Geneva, for their helpful comments and advice; also Dr. G. B. White of the London School of Hygiene and Tropical Medicine; but our chief debt of gratitude goes to the numerous field workers who have continued their efforts to collect representative samples of anopheline blood-meals, often under conditions of severe difficulty.

\section{References}

BlaCK, R. H. (1968). Manual of epidemiology and epidemiological services in malaria programmes.-223 pp. Geneva, WHO.

Boorman, J., Mellor, P. S., Boreham, P. F. L. \& Hewett, R. S. (1977). A latex agglutination test for the identification of blood-meals of Culicoides (Diptera: Ceratopogonidae).-Bull. ent. Res. 67, 305-311.

BorehaM, P. F. L. (1972). Serological identification of arthropod bloodmeals and its application.--PANS 18, 205-209.

BoREHAM, P. F. L. (1975). Some applications of bloodmeal identifications in relation to the epidemiology of vector-borne tropical diseases.-J. trop. Med. Hyg. 78, 83-91.

Boreham, P. F. L. \& Garrett-Jones, C. (1973). Prevalence of mixed blood meals and double feeding in a malaria vector (Anopheles sacharovi Favre).-Bull. Wld Hlth Org. 48, 605-614.

Bruce-Chwatt, L. J. \& Göckel, C. W. (1960). A study of the blood-feeding patterns of Anopheles mosquitos through precipitin tests.-Bull. Wld Hlth Org. 22, 685-720.

Bruce-Chwatt, L. J., Garrett-Jones, C. \& Weitz, B. (1966). Ten years' study (1955-64) of host selection by anopheline mosquitos.-Bull. Wld Hlth Org. 35, 405-439.

Carnevale, P. \& Boreham, P. F. L. (1978). Études des préférences trophiques d'Anopheles nili (Theo.), 1904.-Cah. ORSTOM, Sér. Entomol. Med. Parasit. 16, 17-22.

Collins, R. T., Jung, R. K., Anoez, H., Sutrisno, R. H. \& Putut, D. (1979). A study of the coastal malaria vectors, Anopheles sundaicus (Rodenwaldt) and Anopheles subpictus Grassi, in South Sulawesi, Sulawesi, Indonesia.-12 pp. Geneva, WHO. (WHO/MAL/79.913; WHO/VBC/79.740.)

Coluzzi, M., Sabatini, A. \& Petrarca, V. (in press)-_Trans. R. Soc. trop. Med Hyg.

Fontaine, R. E., Joshi, G. P. \& Pradhan, G. D. (1975). Entomological evaluation of fenitrothion (OMS-43) as a residual spray for the control of An. gambiae and An. funestus, Kisumu, Kenya.-22 pp. Geneva, WHO. (WHO/VBC/75.547; WHO/MAL/ 75.854.)

Fontaine, R. E., Pull, J., Payne, D., Pradhan, G. D., Joshi, G. P. \& Pearson, J. A. (1976). Evaluation of fenitrothion (OMS 43) for malaria control in a large-scale epidemiological trial, Kisumu, Kenya.-43 pp. Geneva, WHO. (WHO/VBC/76.645.)

Fontaine, R. E., Pull, J. H., Payne, D., Pradhan, G. D., Joshi, G. P., Pearson, J. A., Thymakis, M. K. \& Ramos Camacho, M. E. (1978). Evaluation of fenitrothion for the control of malaria.-Bull. Wld Hlth Org. 56, 445-452.

GARRETT-JoNES, C. (1964). The human blood index of malaria vectors in relation to epidemiological assessment.-Bull. Wld Hlth Org. 30, 241-261.

Highton, R. B., Bryan, J. H., Boreham, P. F. L. \& Chander, J. A. (1979). Studies on the sibling species $A$ nopheles gambiae Giles and $A$. arabiensis Patton (Diptera: Culicidae) in the Kisumu area, Kenya.-Bull. ent. Res. 69, 43-53.

Joshi, G. P., Fontaine, R. E., Thymakis, K. \& Pradhan, G. D. (1973). The cause of occasional high counts of $A n$. gambiae in morning pyrethrum spray collections in huts sprayed with fenitrothion, Kisumu, Kenya.-Mosquito News 33, 29-38 
Joshi, G. P., Self, L. S., Usman, S., Pant, C. P., Nelson, M. J. \& Supalin (1977). Ecological studies on Anopheles aconitus in the Semarang area of central Java, Indonesia. 15 pp. Geneva, WHO. (WHO/VBC/77.677.)

Joshi, G. P., Service, M. W. \& Pradhan, G. D. (1975). A survey of species A and B of the Anopheles gambiae Giles complex in the Kisumu area of Kenya prior to insecticidal spraying with OMS-43 (fenitrothion).-Ann. trop. Med. Parasit. 69, 91-104.

Macdonald, G. (1952). The analysis of the sporozoite rate.-Trop. Dis. Bull. 49, 569-86.

MacDonald, G. (1957). The epidemiology and control of malaria.-201 pp. London, Oxford University Press.

Molineaux, L. \& Gramiccia, G. (in press). The Garki project.-Bull. Wld Hlth Org.

REISEN, W. K. \& Boreham, P. F. L. (1979). Host selection patterns of some Pakistan mosquitoes.-Am. J. trop. Med. Hyg. 28, 408-421.

Service, M. W., Joshi, G. P. \& Pradhan, G. D. (1978). A survey of Anopheles gambiae (species A) and An. arabiensis (species B) of the An. gambiae Giles complex in the Kisumu area of Kenya following insecticidal spraying with OMS-43 (fenitrothion).Ann. trop. Med. Parasit. 72, 377-386.

WEITZ, B. (1956). Identification of blood meals of blood-sucking arthropods.-Bull. Wld Hlth Org. 15, 473-490.

White, G. B. (1974). Anopheles gambiae complex and disease transmission in Africa.-Trans. R. Soc. trop. Med. Hyg. 68, 278-301.

WhIte, G. B. (1978). Systematic reappraisal of the Anopheles maculipennis complex.-Mosq. Syst. 10, 13-44.

White, G. B. \& Rosen, P. (1973). Comparative studies on sibling species of the Anopheles gambiae Giles complex (Dipt., Culicidae). II. Ecology of species A and B in savanna around Kaduna, Nigeria, during transition from wet to dry season.-Bull. ent. Res. 62, 613-625.

World Health Organization (1963). Terminology of malaria and of malaria eradication, Report of a drafting committee.-127 pp. Geneva, WHO.

World Health Organization (1975). Manual of practical entomology in malaria. Part 1. Vector bionomics and organization of anti-malaria activities. $-160 \mathrm{pp}$. Part II. Methods and techniques. -191 pp. Geneva, WHO. (WHO Offset Publication no. 13.)

World Health Organization (1978). Director General's Report to 31st World Health Assembly (WHO doc. A31/19, Geneva), 32 pp. 


\section{APPENDIX}

The average frequency of primate blood, compared with that of bovine and other blood in 'aggregated samples' of Anopheles blood-meals, 1971-1978 ${ }^{1}$

Species

Country Year

A. aconitus

Indonesia

Wiedemann

El Salvador

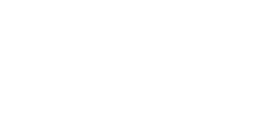

A. annularis

Nepal ${ }^{5}$

A. balabacensis

Bangladesh

Malaysia

(Sabah)

A. barbirostris Wulp Indonesia

A. campestris Reid

Malaysia

A. culicifacies

Afghanistan

Oman Spray
status
of area No. of
+ve primate blood
smears

$\begin{array}{ll}1972 & \text { ex-DDT } \\ 1973 & \text { DDT } \\ 1975 & \text { DDT } \\ 1976 & \text { DDT } \\ 1977 & \mathbf{N}\end{array}$

1977

$\begin{array}{lr}\text { O } & 269 \\ \text { H } & 123 \\ \text { O } & 1513 \\ \text { H } & 50 \\ \text { O } & 320 \\ \text { O } & 210 \\ \text { H } & 20 \\ \text { O } & 671 \\ \text { H } & 8 \\ \text { O } & 425 \\ \text { H } & 28 \\ \text { O } & 691 \\ \text { O } & 370 \\ \text { O } & 973 \\ \text { O } & 100\end{array}$

No. No.

+ve tre

bovine other

blood hosts

$\begin{array}{rcrr}59 & 21.9 & 202 & 8 \\ 7 & 5 \cdot 7 & 116 & 0 \\ 151 & 10 \cdot 0 & 1347 & 35 \\ 3 & 6 & 47 & 0 \\ 25 & 7 \cdot 8 & 287 & 8 \\ 69 & 32 \cdot 9 & 107 & 34 \\ 2 & - & 18 & 0 \\ 12 & 1 \cdot 8 & 658 & 0 \\ 1 & -7.8 & 7 & 0 \\ 12 & 2 \cdot 8 & 413 & 1 \\ 8 & 29 & 20 & 0 \\ 25 & 3 \cdot 6 & 664 & 2 \\ 3 & 0 \cdot 8 & 367 & 0 \\ 81 & 8 \cdot 3 & 887 & 6 \\ 2 & 2 \cdot 0 & 98 & 0\end{array}$

$\begin{array}{llllll}C^{2} & 657 & 135 & 20 \cdot 5 & 495 & 27\end{array}$

PPX

CPS

CPM

PPX

48
447

$\begin{array}{lr}0 & 37 \\ 0 \cdot 0 & 398\end{array}$

$\begin{array}{rrrr}12 & 15 & 0 & 67\end{array}$

11
49
67

$\begin{array}{ll}1972- & \text { DDT } \\ 1974 & \text { 1976- }\end{array}$

$3 \cdot 2 \quad 930$

0 240

$5 \cdot 6 \quad 293$

1
1
29

1977

983
241
340

340
158

19
0

136

22

1973

DDT

$\begin{array}{ll}\text { C } & 82 \\ \text { O } & 12\end{array}$

1971

DDT

26
7

32

$\begin{array}{rr}57 & 0 \\ 5 & 0\end{array}$

23

25

56

13

1974

1976

$\mathbf{N}$

$\begin{array}{lr}\mathrm{O} & 33 \\ \mathrm{C} & 276\end{array}$

$\begin{array}{llrr}0 & 0 & 32 & 1 \\ 9 & 3.3 & 267 & 0\end{array}$

1973

1974

DDT

C

$\begin{array}{lll}8 & 23 & 27\end{array}$

0

35
80

$\begin{array}{lll}0 & 0 & 74\end{array}$

6

4

$\begin{array}{lrr}5 & 75 & 2 \\ 4.5 & 140 & 9\end{array}$

81
156

54

$20 \quad 37$

Notes on Appendix

'Aggregated samples' refers to the sum of blood-meals from all localities where samples were taken for the given species, country, year, etc.

Meals of patent mixed origin are counted once in column 6 but twice in the later columns; e.g. in 1513 smears from A. aconitus in 1973, 20 were found to contain blood of mixed origins giving a total of 1533 determinations.

Spray status refers only to house-spraying of the area with a residual insecticide.

Abbreviations: $\mathbf{N}=$ never sprayed, $M L T=$ malathion, FTT $=$ fenitrothion, $F T N=$ fenthion, $C P S=$ chlorpyrifos, CPM = chlorphoxim, PPX = propoxur, 'ex-DDT', etc., shows that an area was last spraved more than 12 months before sampling.

Biotope-class $\mathrm{H}$ comprises human and mixed dwellings where man is available as host through the night. Class $O$ covers all daytime-resting biotopes where man is not available at night. Class $C$ refers to smears collected experimentally under controlled conditions, e.g. in traps or cages with a choice of baits; such collections usually measure host preference rather than host selection, as defined by Boreham \& Garrett-Jones (1973).

Percentages are shown to one decimal place in samples of 100 and over and as integers in samples of 25-99. No percentage is computed in samples of under 25 smears.

Aggregated samples of fewer than 10 positive smears have been excluded.

1 Summarised from the blood precipitin test results reported to WHO.

2 Collected by night "in immediate vicinity of baits". These were presumably human and animal baits stationed outdoors.

3 From palm-frond roof of a store house.

1 Trapped when entering houses after feeding elsewhere.

5 Years are combined for $A$. annularis, as in other species showing no change of host-selection pattern.

(L 3758) 


\begin{tabular}{|c|c|c|c|c|c|c|c|c|c|}
\hline \multirow[t]{3}{*}{ Species } & Country & Year & $\begin{array}{l}\text { Spray } \\
\text { status } \\
\text { of area }\end{array}$ & $\begin{array}{l}\text { Biotope } \\
\text { class }\end{array}$ & $\begin{array}{l}\text { No. of } \\
\text { + ve } \\
\text { smears }\end{array}$ & $\begin{array}{l}+v \\
\text { primal } \\
\text { No. }\end{array}$ & $\begin{array}{l}\text { for } \\
\text { e blood } \\
\%\end{array}$ & $\begin{array}{c}\text { No. } \\
\text { +ve } \\
\text { bovine } \\
\text { blood }\end{array}$ & $\begin{array}{l}\text { No. } \\
\text { +ve } \\
\text { other } \\
\text { hosts }\end{array}$ \\
\hline & \multirow[t]{2}{*}{ Sri Lanka } & \multirow{2}{*}{$\begin{array}{c}1972- \\
73 \\
1974- \\
75 \\
1976\end{array}$} & DDT & $\mathbf{H}$ & 966 & 121 & $12 \cdot 5$ & 695 & 123 \\
\hline & & & $\begin{array}{c}\text { DDT } \\
\text { DDT } \\
\text { DDT } \\
\text { ex-DDT } \\
\text { MLT } \\
\text { DDT } \\
\text { ex-DDT } \\
\text { MLT } \\
\text { ex-DDT } \\
\text { MLT }\end{array}$ & $\begin{array}{l}\mathbf{H} \\
\mathbf{O} \\
\mathbf{H} \\
\mathbf{H} \\
\mathbf{H} \\
\mathbf{H} \\
\mathbf{H} \\
\mathbf{H} \\
\mathbf{H} \\
\mathbf{H}\end{array}$ & $\begin{array}{r}63 \\
75 \\
296 \\
390 \\
125 \\
379 \\
441 \\
500 \\
70 \\
123\end{array}$ & $\begin{array}{r}9 \\
5 \\
35 \\
139 \\
29 \\
120 \\
99 \\
258 \\
39 \\
81\end{array}$ & $\begin{array}{l}14 \\
7 \\
11 \cdot 8 \\
35 \cdot 6 \\
23 \cdot 2 \\
31 \cdot 7 \\
22 \cdot 6 \\
51 \cdot 6 \\
56 \\
65 \cdot 8\end{array}$ & $\begin{array}{r}37 \\
65 \\
223 \\
239 \\
85 \\
227 \\
287 \\
162 \\
21 \\
26\end{array}$ & $\begin{array}{l}17 \\
5 \\
38 \\
13 \\
11 \\
33 \\
55 \\
80 \\
10 \\
16\end{array}$ \\
\hline A. dthali Patton & Yemen D.R. & 1974 & $\mathbf{N}$ & $\mathbf{H}$ & 49 & 1 & 2 & 32 & 16 \\
\hline \multirow[t]{2}{*}{$\begin{array}{l}\text { A. farauti Laveran } \\
\text { s.1. }\end{array}$} & $\begin{array}{l}\text { British } \\
\text { Solomon Islands }\end{array}$ & 1971 & $\mathbf{N}$ & $\mathbf{H}$ & 11 & 10 & 一 & 0 & I \\
\hline & $\begin{array}{l}\text { Papua New } \\
\text { Guinea }\end{array}$ & $\begin{array}{r}1974- \\
78\end{array}$ & $\stackrel{\mathbf{N}}{\mathbf{N}}$ & $\begin{array}{l}\mathbf{H} \\
\mathbf{O} \\
\mathbf{O}\end{array}$ & $\begin{array}{l}52 \\
49 \\
74\end{array}$ & $\begin{array}{l}48 \\
21 \\
41\end{array}$ & $\begin{array}{l}92 \\
43 \\
55\end{array}$ & $\begin{array}{l}0 \\
0 \\
2\end{array}$ & $\begin{array}{r}4 \\
28 \\
31\end{array}$ \\
\hline \multirow[t]{2}{*}{ A. fluviatilis } & Afghanistan & 1973 & DDT & $\begin{array}{l}\mathbf{H} \\
\mathbf{O}\end{array}$ & $\begin{array}{l}10 \\
16\end{array}$ & $\begin{array}{l}\mathbf{0} \\
\mathbf{0}\end{array}$ & 二 & $\begin{array}{r}8 \\
15\end{array}$ & $\begin{array}{l}2 \\
1\end{array}$ \\
\hline & Pakistan & 1971 & $\begin{array}{l}\mathbf{N} \\
\text { DDT }\end{array}$ & $\begin{array}{l}\mathbf{H} \\
\mathbf{H} \\
\mathbf{O}\end{array}$ & $\begin{array}{l}16 \\
64 \\
92\end{array}$ & $\begin{array}{l}\mathbf{0} \\
\mathbf{0} \\
\mathbf{0}\end{array}$ & $\begin{array}{l}\overline{0} \\
0\end{array}$ & $\begin{array}{l}16 \\
59 \\
85\end{array}$ & $\begin{array}{l}0 \\
5 \\
7\end{array}$ \\
\hline \multirow[t]{14}{*}{ A. funestus group } & Benin & 1977 & $\mathbf{N}$ & H & 45 & 44 & 98 & $\mathbf{0}$ & 1 \\
\hline & Ethiopia & 1971 & ex-DDT & $\mathbf{H}$ & 142 & 139 & 97.9 & $\mathbf{0}$ & 3 \\
\hline & \multirow[t]{2}{*}{$\begin{array}{l}\text { Kenya } \\
\text { (Kisumu) }\end{array}$} & 1971 & $\mathbf{N}$ & $\mathbf{H}$ & 65 & 65 & 100 & 1 & 0 \\
\hline & & $\begin{array}{l}1972 \\
1973 \\
1975\end{array}$ & $\begin{array}{l}\mathbf{N} \\
\mathbf{N} \\
\mathbf{N} \\
\mathbf{N} \\
\mathbf{N} \\
\mathbf{N}\end{array}$ & $\begin{array}{l}\mathbf{H} \\
\mathbf{O} \\
\mathbf{H} \\
\mathbf{O} \\
\mathbf{H} \\
\mathbf{O}\end{array}$ & $\begin{array}{r}653 \\
11 \\
1086 \\
10 \\
349 \\
13\end{array}$ & $\begin{array}{r}646 \\
0 \\
1012 \\
10 \\
342 \\
9\end{array}$ & $\begin{array}{l}98 \cdot 9 \\
\overline{93 \cdot 2} \\
\overline{98 \cdot 0} \\
-\end{array}$ & $\begin{array}{r}5 \\
11 \\
63 \\
0 \\
6 \\
4\end{array}$ & $\begin{array}{r}2 \\
0 \\
11 \\
0 \\
1 \\
0\end{array}$ \\
\hline & Madagascar & 1971 & ex-DDT & $\mathbf{O}$ & 24 & 6 & $\longrightarrow$ & 16 & 2 \\
\hline & Malawi & 1973 & $?$ & $\mathbf{H}$ & 63 & 63 & 100 & 0 & $\mathbf{0}$ \\
\hline & Mozambique & 1978 & $\mathbf{N}$ & $\mathbf{H}$ & 67 & 61 & 91 & 5 & 1 \\
\hline & \multirow{2}{*}{$\begin{array}{l}\text { Nigeria (Bendel } \\
\text { State) }\end{array}$} & 1977 & $\mathbf{N}$ & $\mathbf{H}$ & 58 & 58 & 100 & 0 & 0 \\
\hline & & 1978 & $\mathbf{N}$ & $\mathbf{H}$ & 23 & 23 & 一 & 0 & 6 \\
\hline & $\begin{array}{l}\text { Nigeria7 (Kano } \\
\text { State) }\end{array}$ & 1971 & $\mathbf{N}$ & $\mathbf{H}$ & 202 & 197 & $97 \cdot 5$ & 0 & 5 \\
\hline & (Kaduna State) & 1977 & $\mathbf{N}$ & $\mathbf{H}$ & 80 & 80 & 100 & 0 & 0 \\
\hline & Rwanda & 1975 & $\mathbf{N}$ & $\mathbf{H}$ & 191 & 188 & $98 \cdot 4$ & $\mathbf{0}$ & 3 \\
\hline & Sudan & 1971 & ex-DDT & $\mathbf{O}$ & 32 & 1 & 3 & 19 & 12 \\
\hline & Togo & 1971 & $\mathbf{N}$ & $\mathbf{H}$ & 164 & 164 & 100 & 0 & $\mathbf{0}$ \\
\hline \multirow[t]{4}{*}{ A. gambiae s.1. } & Benin & $\begin{array}{l}1975 \\
1977\end{array}$ & $\stackrel{N}{N}$ & $\begin{array}{l}\mathbf{H} \\
\mathbf{H}\end{array}$ & $\begin{array}{l}58 \\
93\end{array}$ & $\begin{array}{l}58 \\
79\end{array}$ & $\begin{array}{r}100 \\
85\end{array}$ & $\begin{array}{l}0 \\
1\end{array}$ & $\begin{array}{r}0 \\
13\end{array}$ \\
\hline & Botswana & 1974 & $\begin{array}{c}\text { FTT } \\
\text { ex-DDT }\end{array}$ & $\begin{array}{l}\mathbf{H} \\
\mathbf{H}\end{array}$ & $\begin{array}{l}48 \\
30\end{array}$ & $\begin{array}{l}44 \\
18\end{array}$ & $\begin{array}{l}88 \\
60\end{array}$ & $\begin{array}{l}0 \\
0\end{array}$ & $\begin{array}{r}4 \\
12\end{array}$ \\
\hline & Cameroun & 1971 & $\mathbf{N}$ & C & 208 & 115 & $55 \cdot 3$ & 3 & 90 \\
\hline & Central African & 1974 & $\mathbf{N}$ & $\mathbf{H}$ & 211 & 211 & 100 & 0 & 0 \\
\hline
\end{tabular}

- Many samples are excluded here as they were taken in special conditions and represent captures by light-trap or the residue of mosquitoes remaining after indoor bait captures, etc. For some years, the normal resting samples collected in May and August have been selected to represent a large bulk of collections through the year. In 1973 only, $A$. funestus and $A$. gambiae were sampled (in unsprayed areas) in mixed dwellings (biotope class $H$ ) and animal sheds (class $O$ ). Class $O$ was represented by pit-shelters in 1972 but by granaries in 1975.

7 The results from Garki (Kano State) are analysed more fully in a forthcoming publication on project WHO/IR-0172 (Molineaux \& Gramiccia, in press). 


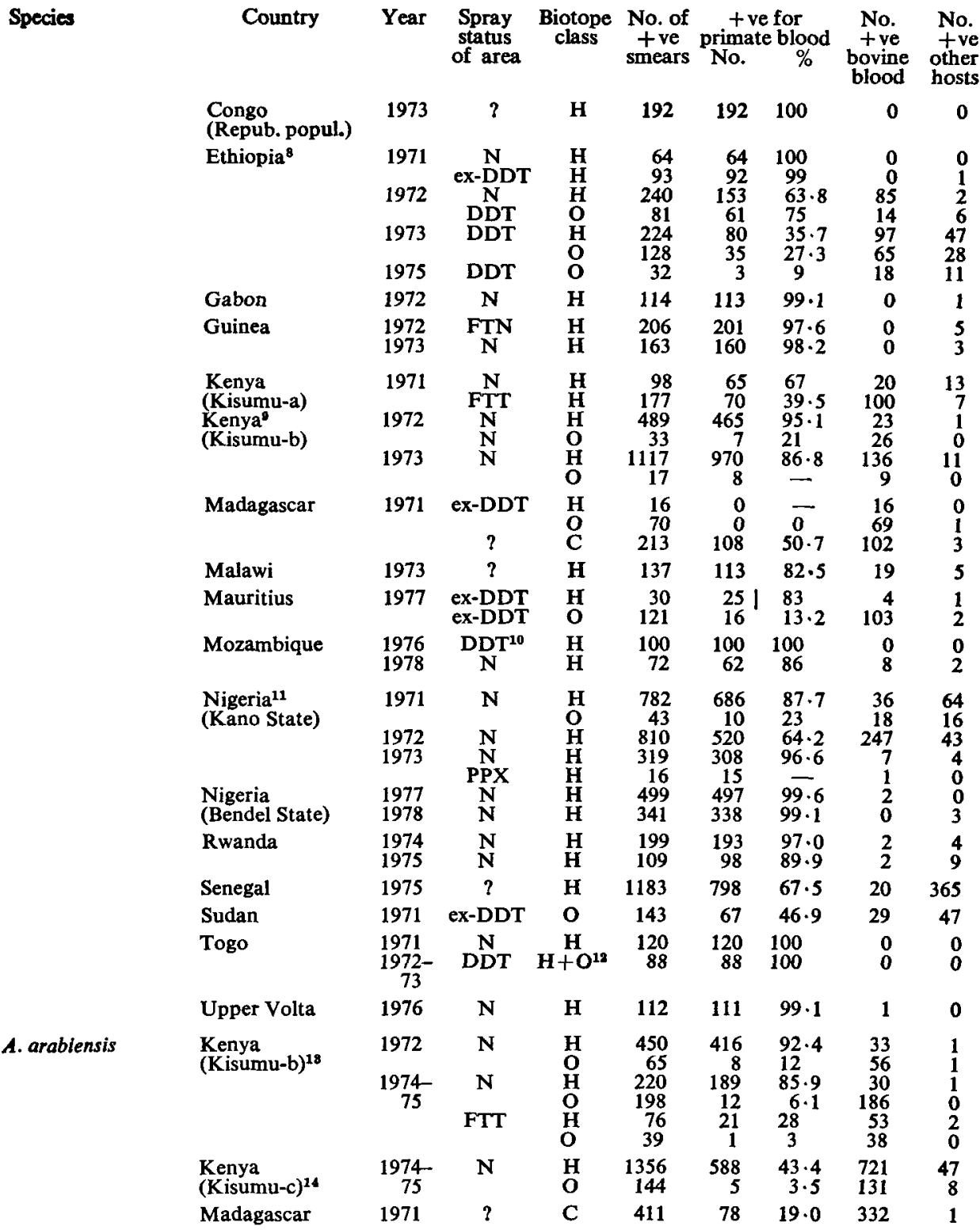

S The 1973 samples from Ethiopia, tabulated here do not refer to the special study conducted by G. B. White and discussed in the text.

- See footnote ${ }^{1}$ under $A$. funestus. These samples were collected by the Anopheles Control Research Unit no. 2 of WHO (see Fontaine et al., 1975, 1976, 1978). For their further records from 1972 and from 1974-75 in the same area, see under $A$. arabiensis and $A$. gambiae s.s.

10 Unsprayed houses in a sprayed area of Mozambique.

11 These results are analysed more fully in a forthcoming publication on project WHO/IR-0172. For records from 1974 and 1975 in the same area, see under $A$. arabiensis and $A$. gambiae s.s. The 1972 sample was collected in a heterogeneous locality; see Discussion.

12 Mostly collected in outlet traps on treated dwellings in March 1973.

13 Biotope class $O$ is represented entirely by pit-shelters in 1972, but by granaries in 1974-75. See Service et al. (1978) for discussion of the 1974-75 findings.

14 Data from Highton et al. (1979). Class $O$ represented by granaries. 
Species

$$
\text { Country Year }
$$

Spray Biotope No. of +ve for No. No. status class + ve primate blood + ve +ve of area smears No. \% bovine other

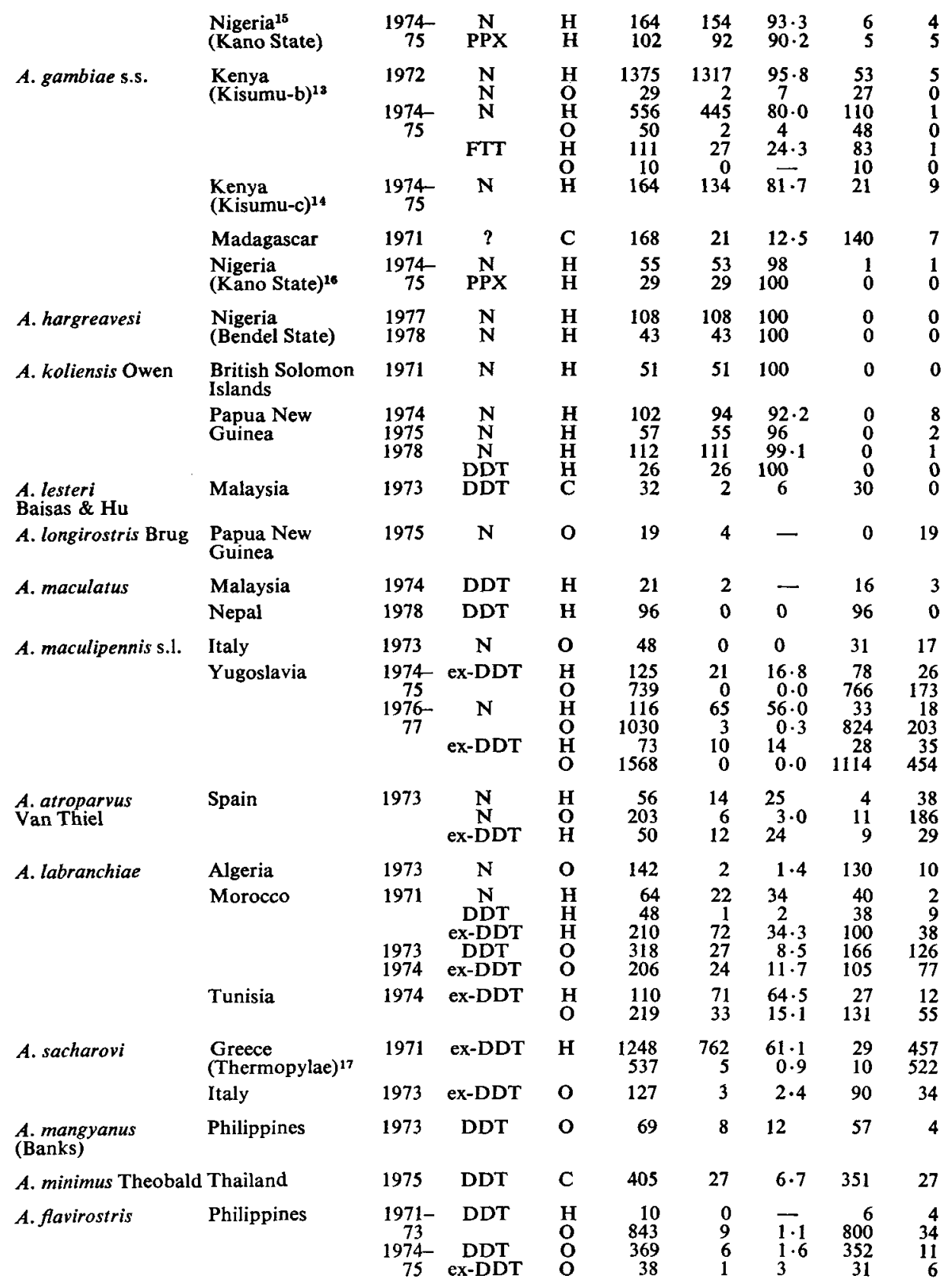

15 See Table 11 and Discussion for separate analysis of samples from Jirima village (Garki).

16 See footnotes under $A$. arabiensis.

17 See Boreham \& Garrett-Jones (1973) for a discussion of multiple feeding in this population. 


\begin{tabular}{|c|c|c|c|c|c|c|c|c|c|}
\hline Species & Country & Year & $\begin{array}{c}\text { Spray } \\
\text { status } \\
\text { of area }\end{array}$ & $\begin{array}{l}\text { Biotope } \\
\text { class }\end{array}$ & $\begin{array}{l}\text { No. of } \\
\text { +ve } \\
\text { smears }\end{array}$ & 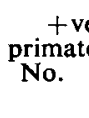 & $\begin{array}{l}\text { for } \\
\text { blood } \\
\%\end{array}$ & $\begin{array}{l}\text { No. } \\
\text { +ve } \\
\text { bovine } \\
\text { blood }\end{array}$ & $\begin{array}{l}\text { No. } \\
\text { +ve } \\
\text { othe } \\
\text { host }\end{array}$ \\
\hline A. moucheti Evans & $\begin{array}{l}\text { Nigeria } \\
\text { (Bendel State) }\end{array}$ & 1978 & $\mathbf{N}$ & $\mathbf{H}$ & 20 & 19 & 一 & 0 & \\
\hline \multirow[t]{2}{*}{ A. multicolor } & Libya & $\begin{array}{c}1973- \\
75\end{array}$ & ex-DDT & $\mathbf{H}$ & 46 & 42 & 91 & 3 & \\
\hline & Tunisia & $\begin{array}{l}1971 \\
1974\end{array}$ & $\stackrel{\mathbf{N}}{\mathbf{N}}$ & $\begin{array}{l}\mathbf{H} \\
\mathbf{H} \\
\mathbf{O}\end{array}$ & $\begin{array}{l}67 \\
94 \\
17\end{array}$ & $\begin{array}{r}44 \\
52 \\
7\end{array}$ & $\begin{array}{l}66 \\
55 \\
-\end{array}$ & $\begin{array}{l}2 \\
1 \\
0\end{array}$ & $\begin{array}{l}21 \\
41 \\
10\end{array}$ \\
\hline \multirow[t]{3}{*}{ A. nili } & Congo $^{18}$ & 1974 & $\mathbf{N}$ & $\mathbf{H}$ & 122 & 107 & $87 \cdot 7$ & 13 & \\
\hline & Brazzaville & & & $\mathrm{H} / \mathrm{O}$ & 1239 & 1191 & $96 \cdot 1$ & 33 & 18 \\
\hline & Togo & 1971 & $\mathbf{N}$ & $\mathbf{H}$ & 59 & 59 & 100 & $\mathbf{0}$ & 0 \\
\hline A. pharoensis & Ethiopia & 1971 & $\mathbf{N}$ & $\mathbf{H}$ & 64 & 60 & 94 & 0 & \\
\hline A. pulcherrimus & Pakistan & 1974 & $\begin{array}{l}\text { DDT } \\
\text { HCH }\end{array}$ & o & 27 & 0 & 0 & 27 & 0 \\
\hline $\begin{array}{l}\text { A.punctulatus } \\
\text { Dönitz }\end{array}$ & $\begin{array}{l}\text { Papua New } \\
\text { Guinea }\end{array}$ & $\begin{array}{c}1974- \\
75 \\
1978\end{array}$ & $\begin{array}{l}\mathbf{N} \\
\mathbf{N}\end{array}$ & $\begin{array}{l}\mathbf{H} \\
\mathbf{O} \\
\mathbf{H}\end{array}$ & $\begin{array}{r}157 \\
12 \\
128\end{array}$ & $\begin{array}{r}154 \\
11 \\
127\end{array}$ & $\frac{98 \cdot 0}{99 \cdot 2}$ & $\begin{array}{l}0 \\
0 \\
0\end{array}$ & \\
\hline A. sergenti & Tunisia & 1971 & $\mathbf{N}$ & $\mathbf{H}$ & 53 & 24 & 45 & 3 & 22 \\
\hline \multirow[t]{3}{*}{ A. stephensi } & Afghanistan & $1972-$ & $\mathrm{DDT}$ & $\mathbf{H}$ & 176 & 4 & $2 \cdot 3$ & 136 & 0 \\
\hline & & 1974 & DDT & $\underset{\mathrm{O}}{\mathrm{H}}$ & $\begin{array}{r}135 \\
98\end{array}$ & $\begin{array}{l}0 \\
0\end{array}$ & $\begin{array}{l}0 \cdot 0 \\
0\end{array}$ & $\begin{array}{r}124 \\
94\end{array}$ & 11 \\
\hline & Saudi Arabia & 1971 & ex-DDT & $\begin{array}{l}\mathrm{H} \\
\mathrm{O}\end{array}$ & $\begin{array}{l}58 \\
42\end{array}$ & $\begin{array}{l}0 \\
0\end{array}$ & $\begin{array}{l}0 \\
0\end{array}$ & $\begin{array}{l}52 \\
42\end{array}$ & 6 \\
\hline \multirow[t]{4}{*}{ A. subpictus } & $\begin{array}{l}\text { Indonesia'18 } \\
\text { (Sulawesi) }\end{array}$ & $\begin{array}{l}1974 \\
1975 \\
1976\end{array}$ & $\begin{array}{l}\mathbf{N} \\
\mathbf{N} \\
\mathbf{N}\end{array}$ & $\begin{array}{l}\mathrm{O} \\
\mathrm{C} \\
\mathrm{C}\end{array}$ & $\begin{array}{r}12 \\
129 \\
916\end{array}$ & $\begin{array}{l}0 \\
3 \\
7\end{array}$ & $\begin{array}{l}\overrightarrow{2.3} \\
0.8\end{array}$ & $\begin{array}{r}12 \\
126 \\
875\end{array}$ & $\begin{array}{l}0 \\
0 \\
4\end{array}$ \\
\hline & Nepal & $\begin{array}{l}1974 \\
1976\end{array}$ & $\begin{array}{l}\mathrm{HCH} \\
\mathrm{DDT}\end{array}$ & $\begin{array}{l}\mathbf{H} \\
\mathbf{O} \\
\mathbf{H} \\
\mathbf{O}\end{array}$ & $\begin{array}{l}93 \\
48 \\
90 \\
45\end{array}$ & $\begin{array}{l}1 \\
0 \\
0 \\
0\end{array}$ & $\begin{array}{l}1 \\
0 \\
0 \\
0\end{array}$ & $\begin{array}{l}92 \\
48 \\
88 \\
43\end{array}$ & \\
\hline & $\begin{array}{l}\text { Papua New } \\
\text { Guinea }\end{array}$ & $\begin{array}{c}1974 \\
75\end{array}$ & $\mathbf{N}$ & $\begin{array}{l}\mathrm{H} \\
\mathrm{O}\end{array}$ & $\begin{array}{r}160 \\
63\end{array}$ & $\begin{array}{l}89 \\
14\end{array}$ & $\begin{array}{l}55 \cdot 6 \\
22\end{array}$ & $\begin{array}{l}0 \\
0\end{array}$ & $\begin{array}{l}73 \\
49\end{array}$ \\
\hline & Sri Lanka & $\begin{array}{c}1971- \\
72\end{array}$ & DDT & $\mathbf{H}$ & 491 & 0 & 0.0 & 483 & \\
\hline $\begin{array}{l}\text { A. sundaicus } \\
\text { (Rodenwaldt) }\end{array}$ & $\begin{array}{l}\text { Indonesia } \\
\text { (Sulawesi) }^{20}\end{array}$ & $\begin{array}{l}1974 \\
1975\end{array}$ & $\begin{array}{l}\mathbf{N} \\
\mathbf{N}\end{array}$ & $\begin{array}{l}\mathrm{H} \\
\mathrm{O} \\
\mathrm{C}\end{array}$ & $\begin{array}{r}212 \\
10 \\
59\end{array}$ & $\begin{array}{r}197 \\
8 \\
43\end{array}$ & $\frac{92 \cdot 9}{73}$ & $\begin{array}{r}15 \\
2 \\
16\end{array}$ & $\begin{array}{l}0 \\
0\end{array}$ \\
\hline $\begin{array}{l}\text { A. tessellatus } \\
\text { Theobald }\end{array}$ & Indonesia & 1976 & $\mathbf{N}$ & $\mathbf{H}$ & 31 & 1 & 3 & 21 & 9 \\
\hline A. vagus Dönitz & $\begin{array}{l}\text { Nepal } \\
\text { Philippines } \\
\text { Nepal }\end{array}$ & $\begin{array}{l}1974- \\
76 \\
1973 \\
1977\end{array}$ & $\begin{array}{l}\text { DDT } \\
\text { DDT } \\
\text { DDT }\end{array}$ & $\begin{array}{l}\mathbf{H} \\
\mathbf{O} \\
\mathbf{H} \\
\mathbf{O}\end{array}$ & $\begin{array}{r}354 \\
222 \\
15 \\
15\end{array}$ & $\begin{array}{l}2 \\
1 \\
0 \\
0\end{array}$ & $\begin{array}{l}0.6 \\
0.4 \\
=\end{array}$ & $\begin{array}{r}351 \\
219 \\
15 \\
15\end{array}$ & 0 \\
\hline
\end{tabular}

18 First sample (122) resting in houses in July 1974, other samples in exit window traps in July 1974 to January 1975 (Carnevale \& Boreham, 1978).

19 Results amended as reported in Collins et al. (1979).

20 Results amended as reported in Collins et al. (1979).

(Received 13 July 1979, revised 19 October 1979).

(C) Commonwealth Agricultural Bureaux, 1980 